ing known as specialists in otology. Among close observers there can be no doubt that, in patients under 15 years of age, an adenoid exists in almost every case of suppuration of the ear. To have any etiological bearing, however, it must promote a chronic congestion of the nasopharynx. In order to serve that purpose, the growth need not be very large, although the greater the adenoid, the more likely will it be to cause trouble in the ears.

Associated with adenoid growths, we commonly encounter a hypertrophy of the faucial tonsils. At the same time, a hypertrophic rhinitis, in which chronic dilatation of the submucous veins of the inferior turbina] body plays the chief rôle, is the prevailing obstruction in the nasal passages.

Posterior turbinal hypertrophies, likewise, obstruct respiration through the nose, and they, too, should be enumerated among the predisposing causes of purulent otitis media.

In view of these facts, it must be obvious to all that rectification of abnormal states of the nose and throat is an indispensable preliminary to the prophylaxis of intracranial and intravenous complications of infectious pyogenic diseases of the ear.

[For Discussion, see The JourNal, xxxiv, p. 1263.]

58 West Fortieth Street.

\section{THE CEREBRAL NEURONS IN RELATION TO MEMORY AND ELECTRICITY**}

SIR JAMES GRANT, K.C.M.G., F.R.S.C., F.R.C.P. LOND. OTTAWA, CANADA.

Professor Heger, ${ }^{1}$ of Brussels, gives an account of experiments made on animals to determine the conditions of the brain cells, during various conditions of rest and stimulation, and concludes that "an important property of the cerebral nerve cell is its variability in reaction as regards its cell body, its processes, and its epidendritic granules. Changes in all three portions may co-exist or occur separately under different conditions. the further significance of which is important, and demands investigation." The nervous system reduced to its initial stage may be represented by two elements, a nerve cell, and a conducting tube, and it is the association of these two elements, which constitutes nerve centers and nerves. Punch tritely remarked, "What is matter never mind, what is mind, that's the matter." Although no relation of identity or analogy subsists, between mind and matter, a close relationship may be shown to exist between mind and force, or between mind force and nerve force. Undoubtedly mental activity may be excited by nerve force, and such is found to be the case in every act in which the mind is excited through the instrumentality of sensorium. The will can develop nerve force, and as a nerve force, can develop mental activity. There is in fact, a correlation between these two forces, fully as intimate as that which exists between nerve force and electricity. Maudsley is of opinion, there is memory in every nerve-cell, and indeed in every organic element of the body. The organic registration of the results of impressions upon our nervous centers, by which memory is established, is'tifter all the very basis of mental life, and the cells and nervous tubes, associated in many ways, constitute the nervous system in its entirety. As life progresses tissue formation changes materially, and we gradually observe the outward as well as the inward manifesta-

- Read before the Royal Soclety of Canada, May 30, 1900.

1. British Medical Journal, May 27, 1899. tions of declining activity. Such is observed in the loss of hair, and the bald scalp, in the decay of teeth and consequent defective power of mastication, so also in the defective auditory process, as well as in gradually impaired vision and memory. Such evidences are undoubted in their character, and positive proof, should such be wanting, of an abnormal decline in systemic power, coincident with advancing years. While these systemic evidences of change are in progress, it is reasonable to infer that nerves and nerve centers, the very motive power of the entire system, should also participate in some degree in those structural modifications, indicative of molecular change, and impaired functional activity. Recent discoveries in the line of nerve-tissue formation, have defined small cellular almost rod-shaped bodies, as components of cell nervous tissue, known as neurons, which take an important place in the elimination of nerve power, and contributing to the production of normal functional activity. One of the most interesting developments recently announced in Germany, France and America, is that nerve cells were capable of movement, to such an extent as to actually alter their original relationship one to the other. In 1890, Wiederschein, a German physiologist, saw in the Leptodara Hyalina, an invertebrate, one of the entomostraca, the nerve cells of the esophageal ganglion move in a slow flowing fashion. This altered relationship almost molecular in character, may give a clue to a lessened functional activity and constitute the basis on which retardation rests. This constitutes the field of action, as to the therapeutic power of the electric current, which, as a known force, is still in its infancy. At the convention of the American Electro-therapeutic Association, ${ }^{2}$ it was stated that static electricity causes contraction of the protoplasm, both animal and vegetable, excites nerve fibers, nerve centers. and nerve cells, to functional action, and to produce their separate effects, motor, sensory, secretory, sympathetic and vasomotor. The recent observation of Professor Herdman, ${ }^{3}$ of the University of Michigan, is as follows: "That whenever a current of electricity traverses an animal body, the magnetic field resulting from the current and surrounding its path, must disturb in some manner the molecular and atomic activities that are going on in the tissues and fluids, through which the current of electricity passes, in fact, in such a manner as to rotate in some degree every molecule, so as to make it assume a different position from what it would if not thus acted upon," and draws the deduction, "that alternating magnetic stress is in some way related to quickened metabolism of tissue; that the magnetic energy goes through some sort of transformation, and reappears as physiological energy." During the past few years, in noting the results of fasling nerve power, as indicated by functional inactivity. in tissues and organs generally, I have been more and more impressed with the vast importance of a thoroughly established balance of power in each structure of the human body and particularly with reference to the nervous system. In the examination, no oroan should be passed over casually, or even section of the bodv, as difficulties creep up almost silently and diseased conditions become established prior to particularly marked external indications of importance defining the same. The brain is the battery of the body and as diversified in its peculiarities and manifestations as the facial expression of the Genus Homo, no two of the entire human species being exactly alike. In the examination of

2. The Times and Register, Dec. 29, 1894

3. Flectricity, April 18, 1900 . 
nerve power by electro-neurotone currents. I noted on several occasions after a few weeks' application quite a change in intellectual activity, as evidenced by improved memory. The currents were passed through the base of brain chiefly, by applications to the parotid regions on either side of the neck, and in the most casual manner, not in the least anticipating this practical result. 'The individuals operated on were over 60 years of age, and the improvement of memory was of such a character as in my humble opinion to be worthy of the closest scientific inquiry.

\section{REPORT OF TWO CASES OF AFEBRILE TYPHOID.}

CHAS. J. WHALEN, M.T., ILL.B., CHICAGO.

1 presume no one thing has aided us so much in the diagnosis of typhoid fever as the temperature chart. Since the use of the clinical thermometer the temperature has come to be the indication for diagnosis, treatment and prognosis. All the old and recent authorities place great emphasis on this symptom of the disease. Indeed, the temperature in typhoid is so absolutely essential for the estimation of each individual case that no scientific physician would treat one without regular measurements of the temperature.

It was formerly considered that typhoid fever had to be accompanied by elevation of temperature, and the rule that at some period of the disease the temperature is raised was supposed to be without an exception. That such a thing as afebrile tvphoid exists has been called to the attention of the profession by Liebermeister. I shall not enumerate the symptoms of this disease, but I wish to show that we may have absence of rise in temperature and yet the case be one of typhoid fever. Within the last few years I have seen patients with undoubted afebrile typhoid, and this has led me to give the subject consideration. My investigation has convinced me that the disease does occur in an endless number of types, and in this connection I desire to call attention to two cases of the afebrile form which came under my observation during the last sixteen months.

CASE 1.-J. E., a clerk, aged 23, whose previous health had been excellent, came to me Sept. 10, 1899, complaining of lassitude, headache, inaptitude for work, constipation quite pronounced, and loss of appetite. The above symptoms had been present for five days, and there was no temperature, but some splenic tenderness. He was given a cathartic with instructions to call again within forty-eight hours. At the end of this time he complained of having had a severe epistaxis on the morning of the sixth day, no temperature, the tongue dry and coated, and tenderness over the spleen more pronounced. I found both the diazo and Widal reactions positive, and this at once confirmed my suspicion of typhoid fever. On the eighth day there appeared a crop of five distinct rose spots. On the tenth there was quite marked iliac tenderness and meteorism present; the pulse was soft and beating 100 per minute. The patient was put to bed, where he remained for three weeks, and during this time his temperature was taken four times daily and the highest degree recorded was 99 . At the end of this time the patient was told that he might go home, but that he was to follow out instructions regarding diet, exercise, etc. On arriving home he disobeyed and partook of a large meal, walked several miles, spent the day and evening in visiting friends, and the following day felt weak and exhausted; on the next day he had headache, no desire for food and felt bad generally. $\mathrm{He}$ continued to grow worse, and, five days afterward I found him with mental torpor and dulness, his tongue and lips dry, a new crop of rose spots on the abdomen, and considerable meteorism present, with a large and tender spleen, temperature 102 and pulse 100. This patient, in his relapse, ran a typical course of severe typhoid fever, his temperature pursuing the stepladder rise and continuing high for four weeks, though he eventually recovered after being in bed two months.

CASE 2.-July 8, 1900, John R., a schoolboy, aged 17, consulted me because of lassitude, intense headache, weakness and gradual loss of appetite, nervousness, inability to sleep and occasional chilliness; he also complained of marked constipation. I found his tongue heavily coated, pulse 106, soft and slightly dicrotic, temperature normal, some iliac tenderness and meteorism present, a crop of rose spots on the abdomen and thorax, Widal and diazo reaction both positive. By July 20 he had improved generally, meteorism had nearly subsided, and he was beginning to crave food, no elevation of temperature had been noted, although it had been taken four times daily after the first visit. From this time on the patient gradually improved, and at the end of three weeks after first consulting me, barring a slight weakness, he was apparently well.

I was taught that typhoid fever had a characteristic course, a step-ladder rise in temperature continuing high for a period ranging from two to four weeks, declining gradually during the third and fourth. I am convinced that we may have genuine typhoid without any rise of temperature. Therefore, the typhoid of to-day is not the typhoid of von Niemeyer, Trousseau, Elint and others, for they portrayed a disease having a fairly constant train of symptoms, a fever with a characteristic course and other equally important conditions varying. Certainly ambulatory and afebrile types of the disease must have been very rare or else were not diagnosed in the practice of the older authors.

34 Washington Street.

A Hospital Steamer for the Philippines.-Major John S. Kulp, surgeon U. S. V., has recently reported the results of a voyage from Manila, on the army transport Pennsylvania, to bring sick men from the outlying islands to the general hospitals in that city. The vessel, a Philadelphia built, tripple-expansion, single-screw iron steamer, of 3343 tons capacity, left Manila Oct. 5, 1900, with a small cargo of subsistence and quartermaster's supplies and accommodation for the return of 160 sick soldiers. Everything necessary for the comfort, welfare and convenience of the sick was furnished promptly from the medical supply depot at Manila. The bunks were ironpipe frumes with woven-wire mattresses, all on the main deck, well ventilated and high above the water line. The vessel called at eighteen ports and brought off 155 patients, returning to Manila November 11, after a voyage of 2332 miles. Thirteen of the patients were affected with diarrhea, 46 with dysentery, 19 with malarial fever and 10 were sufferers trom gunshot wounds. No death occurred during the trip, although many of the cases when received were of a grave character. In every ease there was a marked improvement, and many were practically well by the end of the voyage. The object of the voyage was to determine whether or not it was practical to make use of one of the inter-island transports for the transportation of the sick during her regular trips. The result from an administrative standpoint was unsatisfactory. It proved that a shin devoted solely to the interests of the medical department was a necessity. Although the cargo was insignificant in amount the voyage was prolonged one-third on account of the delays caused by its delivery. Col. Greenleaf, chief surgeon of the Division of the Philippines, states that authority has been received from the U. S. secretary of war to purchase a lightdraught ship for use as an inter-island hospital transport, and that measures are now on foot to effect this object, which will solve satisfactorily the question of furnishing the provincial military hospitals with supplies and removing their sick when necessary. 